\title{
A Single-step Process to Convert Karanja Oil to Fatty Acid Methyl Esters Using Amberlyst15 as a Catalyst
}

\author{
Arun K. Gupta ${ }^{a, *}$ and G. Deo ${ }^{b}$ \\ aDepartment of Chemical Engineering, \\ University Institute of Engineering and Technology, \\ CSJM University, Kanpur 208024, India \\ ${ }^{b}$ Department of Chemical Engineering, \\ Indian Institute of Technology Kanpur, Kanpur, 208016, India
}

\section{doi: 10.15255/CABEQ.2017.1201}

Original scientific paper Received: August 23, 2017 Accepted: February 13, 2018

\begin{abstract}
Karanja oil was successfully converted to fatty acid methyl esters (FAME) in a single-step process using Amberlyst15 as a catalyst. A methanol to oil ratio of 6 was required to retain the physical structure of the Amberlyst15 catalyst. At higher methanol to oil ratios, the Amberlyst15 catalyst disintegrated. Disintegration of Amberlyst15 caused an irreversible loss in catalytic activity. This loss in activity was due to a decrease in surface area of Amberlyst15, which was caused by a decrease in its mesoporous volume. It appeared that the chemical nature of Amberlyst15 was unaffected. Reuse of Amberlyst15 with a methanol to oil ratio of 6:1 also revealed a loss in FAME yield. However, this loss in activity was recovered by heating the used Amberlyst 15 catalyst to $393 \mathrm{~K}$. The kinetic parameters of a power law model were successfully determined for a methanol to oil ratio of $6: 1$. An activation energy of $54.9 \mathrm{~kJ} \mathrm{~mol}^{-1}$ was obtained.
\end{abstract}

Keywords:

Karanja oil, Amberlyst15, FAME, biodiesel, methanol to oil ratio, kinetic parameters

\section{Introduction}

Biodiesel production from plant oils has been successfully achieved by using solid and liquid phase catalysts. ${ }^{1-5}$ During this catalytic process, the triglycerols and free fatty acids (FFAs) in the plant oils are converted to FAME, which is biodiesel. ${ }^{6}$ Solid catalysts have several advantages over liquid phase catalysts for biodiesel production from plant oils. ${ }^{7,8}$ Amongst the most important advantage is the ease of separation of the catalyst from the reaction mixture, which makes the solid catalyzed processes amenable for continuous operations. Furthermore, the use of non-edible oils as raw material for biodiesel production is important, especially when the cost of edible oils and diesel are comparable. However, non-edible oils are known to contain FFAs, ${ }^{9}$ which make the processes using basic catalysts complicated due to the consumption of the base. ${ }^{10}$ The base catalyst is consumed by FFAs to form soap instead of being involved in the catalytic reaction. To overcome this situation, the excess of base catalyst has been used. ${ }^{11}$

To enable the use of non-edible oils for biodiesel production, different process strategies have been proposed. ${ }^{12,13}$ In one of the processes, the FFAs were first removed from non-edible oil by adsorption or reaction by a suitable adsorbent or acid cat-

\footnotetext{
${ }^{*}$ Corresponding author: Contact no.: +919451986242; e-mail: arung247@gmail.com
}

alyst, and then the FFA-free non-edible oil was further processed by a basic catalyst. These processes can be clubbed as two-step processes. In another process, the non-edible oils containing FFAs are processed in a single-step by using an acid catalyst. In the single-step process it is important to use an effective acid catalyst for biodiesel production. ${ }^{6}$ Sulfuric acid is a common liquid phase acid catalyst that has been used for biodiesel production from non-edible oils containing FFAs. ${ }^{14,15}$ However, solid acid catalysts are materials of choice due to reasons mentioned above. Furthermore, storage and safety issues related to sulfuric acid are common deterrents. ${ }^{16}$

Several non-edible oils containing FFAs have been tested for biodiesel production. ${ }^{17}$ In India, Karanja oil as the raw material for biodiesel production deserves special attention due to agronomic predictions. ${ }^{9}$ The amount of FFAs present in Karanja oil range from $3 \%$ to $20 \%{ }^{15,18-20}$ Hence, the use of base catalyst for biodiesel production is severely limited..$^{18}$ Acid catalysts have been used to produce biodiesel from Karanja oil with varying degrees of success. ${ }^{15,18}$ Of the various acid catalysts, acidic resins are an important class of solid acid catalysts used for biodiesel production. ${ }^{21}$ One important acidic resin used as a solid acid catalyst for biodiesel production is Amberlyst15. Amberlyst15 is a sulfonic acid cation exchange resin containing styrene divinylbenzene copolymer. ${ }^{22,23}$ Amberlyst15 has 
shown higher yield compared to other acidic catalysts, such as ZeoliteY, ZeoliteZSM, Zeolite $\beta$, Zeolite mordenite and wet Amberlyst15. ${ }^{24}$ Amberlyst15 has been used as acidic resin for biodiesel production from non-edible oils containing FFAs. ${ }^{24-27} \mathrm{Am}$ berlyst15 has shown higher porosity, surface area and better temperature stability compared to other cation resins, such as Amberlyst 31, Amberlyst 35, and Amberlyst $36 .{ }^{33}$ However, the use of Amberlyst 15 for biodiesel production from Karanja oil appears to be missing. This forms the basis of the present study.

In the present study, the possibility of a onestep process for converting Karanja oil to FAME using Amberlyst 15 was examined. Other non-edible oils (Jatropha and Linseed) and edible oil (Soybean) using Amberlyst15 were also tested and compared. The effect of operating parameters on the biodiesel production from Karanja oil to FAME was studied, and appropriate operating conditions were proposed. The operating parameters included: (i) reaction temperature, (ii) methanol pretreatment, and (iii) methanol:oil ratio. Catalyst reusability and regeneration was also considered. Finally, the kinetic parameters for the consumption of triglycerol were determined using a power law model. Although formation of FAME is the most important chemical conversion, there are several other properties of biodiesel that also need to be tested before the converted plant oil can be considered as biodiesel. Such properties are not considered in the present work.

\section{Materials and methods}

\section{Material used}

The non-edible oil sources used in the present study for FAME production were Karanja oil, Jatropha oil, and Linseed oil. Soybean oil, an edible oil, was also used for comparison. These oils were purchased from the local market of Kanpur district, Uttar Pradesh, India. Methanol (99 \% purity, Merck) was the other reactant, and Amberlyst15 (moisture up to $5 \%$, Sigma Aldrich) was used as the catalyst.

\section{Reactor setup}

A stainless steel batch reactor of 2 L capacity (length $30 \mathrm{~cm}$, diameter $15 \mathrm{~cm}$ ) with impeller (diameter $6 \mathrm{~cm}$ ) was used for FAME production in this study. The reactor was electrically heated and temperature was controlled with a cooling water circulation system. The temperature of the reactor was measured by a PT-100 temperature sensor and controlled by a PID controller (Selec, Model PID 500). Samples of the reaction mixture were taken from the valve provided at the bottom of the reactor. A

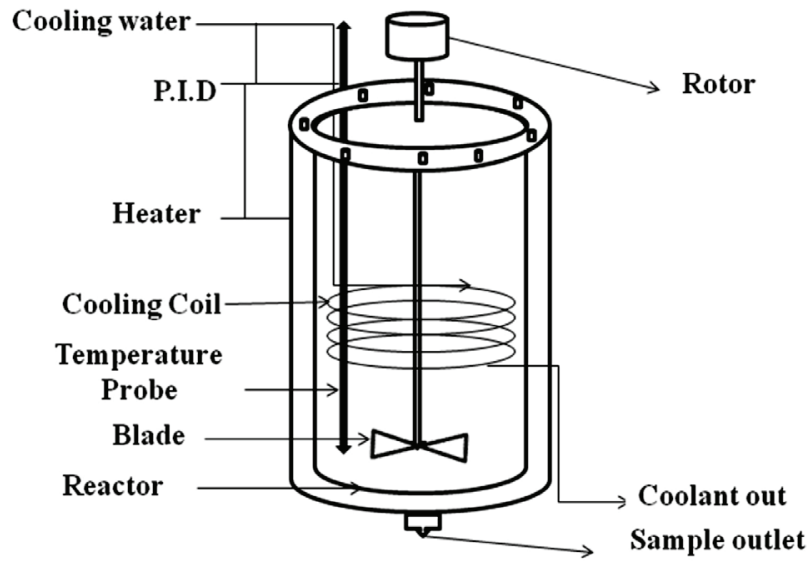

Fig. 1 - Schematic of the batch reactor

schematic of the batch reactor is given in Fig. 1. An earlier study used the same batch reactor for FAME production. $^{28}$

\section{Catalyst characterization}

Scanning electron microscopy (SEM) studies were carried out with a TESCAN (MIRA3) instrument under high vacuum mode using an SE detector and $5 \mathrm{kV}$ beam voltage. Thermal gravimetric analysis (TGA) was achieved using a DSC-TGA Q series (SDT Q600) instrument equipped with a platinum-platinum $/ 13 \%$ rhodium Type $\mathrm{R}$ thermocouple and an alumina sample cup holder. For TGA, about $6 \mathrm{mg}$ of the sample was heated at a rate of 20 ${ }^{\circ} \mathrm{C}$ min $^{-1}$ in a stream of flowing $\mathrm{N}_{2}$. The weight loss of the sample versus temperature was collected and used for analysis. The BET surface area and pore volumes of the samples were obtained from the amount of $\mathrm{N}_{2}$ adsorbed. The amount of $\mathrm{N}_{2}$ adsorbed was measured by an Autosorb-1C instrument (Model AS1-C, Qantachrome, USA).

\section{Reaction and analysis}

Production of FAME was performed with a constant volume of reaction mixture $(341 \mathrm{~mL})$. The reactants were known amounts of oil, methanol, and catalyst. The reactants and catalyst were added to the batch reactor and the reactor top was sealed. After sealing the reactor, the reaction mixture was heated to the desired reaction temperature. The reaction mixture was also agitated with a pitched turbine at $750 \mathrm{rpm}$ during the heating process and until the end of the reaction. The heating rate was such that the reaction mixture took less than $1 \mathrm{~h}$ to reach the set-point temperature. The reaction time was measured after reaching the set-point and the reaction was continued for $8 \mathrm{~h}$.

To determine the amounts of reactants and products, samples were withdrawn after pre-determined time intervals and kept in an ice-bath to 
quench the reaction. After $8 \mathrm{~h}$ of reaction, heating of the reactor vessel was stopped and the reactor vessel was allowed to cool to room temperature. Before analysis, the collected samples were washed with hot (about $70{ }^{\circ} \mathrm{C}$ ) double distilled water. The separated oil-rich samples, free from methanol, glycerol, and water, were analyzed with ${ }^{1} \mathrm{H}$ NMR spectroscopy. From the peak areas of the $\alpha-\mathrm{CH}_{2}$, glyceridic, and methyl ester protons, the FAME yields were determined using previously established procedures. ${ }^{29}$ As previously noted, the glyceridic proton for the mono-, di- and triglycerols were in the same region and analyzed together. ${ }^{30}$ Several runs were conducted for some samples to analyze the variations in each run. An average of less than $5 \%$ variation in yield was observed.

\section{Estimation of kinetic parameters}

A power law model for the reaction was considered for the estimation of kinetic parameters and kinetic analysis. To estimate the kinetic parameters of the power law model, the FAME formation reaction was carried out at 353,373 , and $393 \mathrm{~K}$ with a methanol to oil ratio of $6: 1$. The concentration of $\alpha-\mathrm{CH}_{2}$, glyceridic, and methyl ester protons were tracked as the reaction progressed and the FAME yield and glyceridic conversion were calculated. From the FAME yield and the glyceridic conversion, the concentration of triglycerol + diglycerol + monoglycerol remaining in the reaction mixture was determined. During this analysis, it was assumed that only triglycerols were present and the direct conversion of triglycerol to FAME had occurred. The rate of consumption of triglycerol, $-r_{T G}$, was related to the concentration of triglycerol, $C_{T G}$, by the following equation:

$$
-r_{T G}=k C_{T G}^{n}
$$

where, $k$ is the rate constant of the reaction, and $n$ is the order of the reaction. In the above power law model, the concentration of methanol was assumed to be in excess and the concentration of methanol was included into the rate constant, $k$, of the power law model. An Arrhenius type of relationship was considered for $k$, i.e.,

$$
k=k_{0} \exp \left[-\frac{E}{R T}\right]
$$

where, $k_{0}$ is the pre-exponential factor, $E$ is the activation energy, $R$ is the universal gas constant and $T$ is the reaction temperature.

The values of $k$ at each temperature were estimated from the experimental data by integral analysis for different values of $n$ using Polymath 5.1. Non-linear regression of the power law model was then applied for a better estimate of the kinetic pa- rameters. Previous studies re-parameterized the rate constants to decrease the correlation between $k_{m}$ and $E .^{30}$ Thus, before non-linear regression, the rate constant was re-parameterized as:

$$
k=k_{m} \exp \left[-\frac{E}{R}\left(\frac{1}{T}-\frac{1}{T_{m}}\right)\right]
$$

where, $k_{m}$ is the rate constant at a mean reaction temperature of $T_{m}$. The value of $T_{m}$ is $373 \mathrm{~K}$. Thus, the modified power law model used for estimating the kinetic parameters by non-linear regression was:

$$
-r_{T G}=k_{m} C_{T G}^{n} \exp \left[-\frac{E}{R}\left(\frac{1}{T}-\frac{1}{T_{m}}\right)\right]
$$

The initial values of $k_{m}, n$ and $E$ that were required for non-linear regression were obtained from integral analysis as estimated above.

\section{Results and discussion}

The Karanja oil used in the present study contained about $6.16 \%$ FFA. Using a solution of $\mathrm{NaOH}$ and methanol as the catalyst, a noticeable amount of soap was formed. Consequently, Karanja oil was not suitable for FAME production using homogeneous base catalysts.

To test the feasibility of the single-step FAME production reaction using Amberlyst15 as the catalyst, the reaction was carried out with methanol to oil ratios of $6: 1,30: 1$, and $60: 1$, and the results are shown in Fig. 2. Fig. 2 reveals that FAME had indeed formed at the three methanol to oil ratios, and the FAME yield increased with reaction time. However, the FAME yield at a particular reaction time changed non-monotonically with the increase in

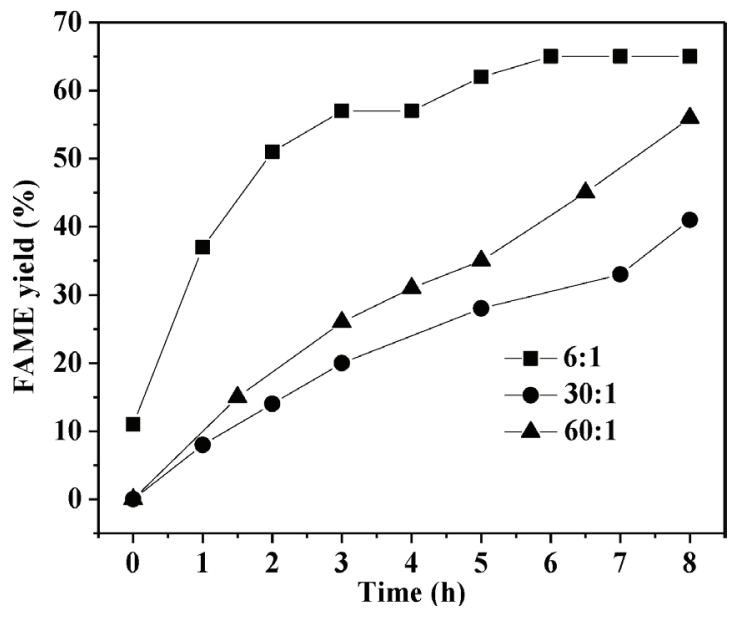

Fig. 2 - FAME yield from Karanja oil at different reaction times for methanol to oil ratio of 6:1, 30:1, and 60:1. Reaction conditions: catalyst amount $=18 \mathrm{wt} \%$ of oil; temperature $=$ $393 \mathrm{~K} ; \mathrm{rpm}=750$; reaction mixture volume $=341 \mathrm{~mL}$. 
methanol to oil ratio. At a particular reaction time with the increase in methanol to oil ratio, the FAME yield decreased and then increased. Previous studies have suggested that the FAME yield monotonically increased with the increase in methanol to oil ratio. ${ }^{32,33}$ To examine the cause for these unexpected results, additional experiments were carried out.

\section{Effect of different oils}

To explore the unusual non-monotonic change of FAME yield with increase in methanol to oil ratio, other non-edible and Soybean oils were also tested for FAME production in a single-step process using Amberlyst 15 as a catalyst. The results of these studies are shown in Table 1. All oils were suitable for FAME production using Amberlyst15 as a catalyst in a single step process. For three of the oils, Karanja, Jatropha and Soybean, the FAME yield decreased when the methanol to oil ratio increased from $6: 1$ to $30: 1$, and then the FAME yield increased when the methanol to oil ratio was increased further from $30: 1$ to $60: 1$. Thus, the non-monotonic change in FAME yield with the increase in methanol to oil ratio was not limited to Karanja oil or to the plant oils that contained FFAs.

The above non-monotonic change in FAME yield was not entirely applicable when Linseed oil was used as the source for FAME production. For Linseed oil, the FAME yield decreased from $61 \%$ for a methanol to oil ratio of $6: 1$ to $55 \%$ for a methanol to oil ratio of 30:1. With further increase in methanol to oil ratio, the FAME yield appeared to approach a constant value of $54 \%$. Such a non-monotonic change for Karanja oil, Jatropha oil and Soybean oil or decrease in FAME yield for Linseed oil with an increase in methanol to oil ratio does not appear to be well documented. Previous studies have used high methanol to oil ratios (greater than 20:1), which may be due to the low reaction rates observed for acid catalyzed conversion of non-edible oil to FAME. ${ }^{33}$

Table 1 - FAME yield for different oils showing the effect of methanol to oil ratio

\begin{tabular}{l|c|c|c}
\hline \multirow{2}{*}{ Oils } & \multicolumn{3}{|c}{ FAME yield (\%) at methanol } \\
& to oil ratio \\
\cline { 2 - 4 } & $6: 1$ & $30: 1$ & $60: 1$ \\
\hline Karanja oil & 65 & 41 & 56 \\
Jatropha oil & 56 & 31 & 54 \\
Linseed oil & 61 & 55 & 54 \\
Soybean oil & 42 & 28 & 34 \\
\hline
\end{tabular}

*Reaction conditions: Catalyst amount $=18 \mathrm{wt} \%$, temperature $=$ $393 \mathrm{~K}, \mathrm{rpm}=750$, time $=8 \mathrm{~h}$, reaction mixture volume $=341 \mathrm{~mL}$.

\section{Effect of reaction times}

To investigate the slightly different behavior of Linseed oil with respect to the increase in methanol to oil ratio, the FAME yield was determined for the different oils as a function of reaction time for a constant methanol to oil ratio of 60:1. The results of these studies are shown in Fig. 3. For Karanja oil, Jatropha oil, and Soybean oil, the FAME yield increased monotonically with time. In contrast, for Linseed oil, the FAME yield increased rapidly in the first $2 \mathrm{~h}$ of the reaction and then approached a constant value of about $55 \%$ during the remaining $6 \mathrm{~h}$ of reaction. To understand the reasons for the different behavior of Linseed oil during the reaction, the properties of the non-edible oils were obtained. Such an analysis was relevant, since non-edible plant oils are extracted from different feedstock and may possess different functional groups. The presence of different functional groups in the non-edible oils would have an effect on the FAME production.

The different properties of Karanja, Jatropha, and Linseed oils were determined and listed in Table 2 and 3. The properties of Soybean oil are not reported since they are often available in the literature. ${ }^{35}$ The physical and chemical properties of the oils determined in Table 2 and 3 were similar to those reported elsewhere. ${ }^{15,36-40}$ Analysis of Table 3 revealed that the chemical constituents of Linseed oil was different from the other oils. In Linseed oil, large amounts of Linoleic acid and smaller amounts of Oleic acid were present. It appeared that Linoleic acid is more readily converted to FAME, giving rise to a faster conversion of Linseed oil to FAME, as shown in Fig. 3. Furthermore, a proper comparison

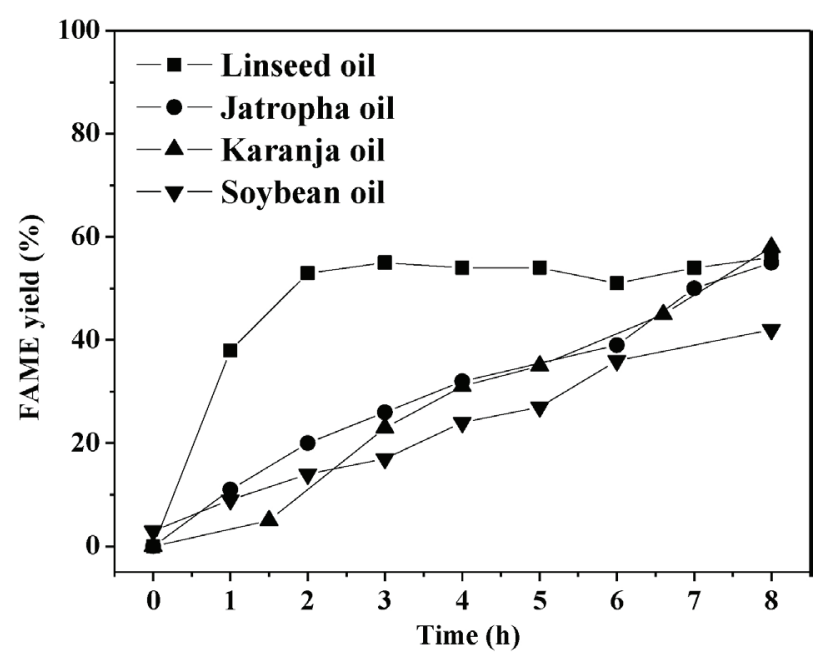

Fig. 3 - FAME yield at different reaction times for different oils. Reaction conditions: oil $=89.26$ g; methanol:oil $=60: 1$; catalyst amount $=18 \mathrm{wt} \%$ of oil; $T=393 \mathrm{~K}$; reaction mixture volume $=341 \mathrm{~mL}$. 
Table 2 - Some characteristic parameters of the non-edible oils used in the present study

\begin{tabular}{|c|c|c|c|}
\hline $\begin{array}{l}\text { Characteristic } \\
\text { parameter }\end{array}$ & Karanja oil & Jatropha oil & Linseed oil \\
\hline Color & Dark brown & Yellowish & Yellowish \\
\hline Odor & Repulsive & Less Repulsive & Repulsive \\
\hline $\begin{array}{l}\text { Acid value } \\
\mathrm{mg} \mathrm{KOH} \mathrm{g}^{-1} \text { oil }\end{array}$ & 12.26 & 7.21 & 6.57 \\
\hline FFA content $(\%)$ & 6.16 & 3.62 & 3.30 \\
\hline Density $\left(\mathrm{g} \mathrm{mL}^{-1}\right)$ & 0.9 & 0.89 & 0.97 \\
\hline Flash point $\left({ }^{\circ} \mathrm{C}\right)$ & 252 & 240 & 260 \\
\hline Fire point $\left({ }^{\circ} \mathrm{C}\right)$ & 261 & 252 & 280 \\
\hline
\end{tabular}

Table 3 -Chemical composition of the non-edible oils used in the present study

\begin{tabular}{lcccc}
\hline \multicolumn{1}{c|}{ Fatty acid } & $\begin{array}{c}\text { Karanja } \\
\text { oil }\end{array}$ & $\begin{array}{c}\text { Linseed } \\
\text { oil }\end{array}$ & $\begin{array}{c}\text { Jatropha } \\
\text { oil }\end{array}$ \\
\hline Myristic acid $\left(\mathrm{C}_{14} \mathrm{H}_{28} \mathrm{O}_{2}\right)$ & - & 3 & 11 \\
Palmitic acid $\left(\mathrm{C}_{16} \mathrm{H}_{32} \mathrm{O}_{2}\right)$ & 5.0 & 2.2 & 18.5 \\
Stearic acid $\left(\mathrm{C}_{18} \mathrm{H}_{36} \mathrm{O}_{2}\right)$ & 5.5 & 4.4 & 13 \\
Oleic acid $\left(\mathrm{C}_{18} \mathrm{H}_{34} \mathrm{O}_{2}\right)$ & 66.0 & 25.3 & 46.5 \\
Linoleic acid $\left(\mathrm{C}_{18} \mathrm{H}_{32} \mathrm{O}_{2}\right)$ & 14.5 & 1.2 & 5 \\
Linolenic acid $\left(\mathrm{C}_{18} \mathrm{H}_{30} \mathrm{O}_{2}\right)$ & - & 50.6 & - \\
Arachidic acid $\left(\mathrm{C}_{20} \mathrm{H}_{40} \mathrm{O}_{2}\right)$ & 4.0 & 3.7 & 1.5 \\
Behenic acid $\left(\mathrm{C}_{22} \mathrm{H}_{44} \mathrm{O}_{2}\right)$ & 5.0 & 9.6 & 4.5 \\
\hline
\end{tabular}

of the different oils in Table 1 should have been done at a reaction time of less than $2 \mathrm{~h}$ instead of the $8 \mathrm{~h}$ reaction time chosen in the present study.

It is also worth noting from Table 2 that the three non-edible oils contained FFA and the FFA content of Karanja oil was the highest. Comparison of the FFA content in the oils with the FAME yield achieved revealed that the presence of FFA was beneficial for achieving higher FAME yields. Previous studies have revealed that FFAs are more readily converted to FAME compared to triglycerols, ${ }^{41}$ which appears to be the reason for the higher FAME yield achieved from Karanja, Jatropha, and Linseed oils.

\section{Effect of catalyst pretreatment with methanol}

Previous studies have revealed that methanol poisons the Amberlyst 15 catalyst ${ }^{24}$ and may cause the unusual behavior of FAME yield with the increase in methanol to oil ratios. The effect of Amberlyst15 pretreatment on the FAME yield from Karanja oil was also examined for different methanol to oil ratios. These results were compared with those achieved with as-received Amberlyst15 in Fig. 4. The results revealed that pretreatment of

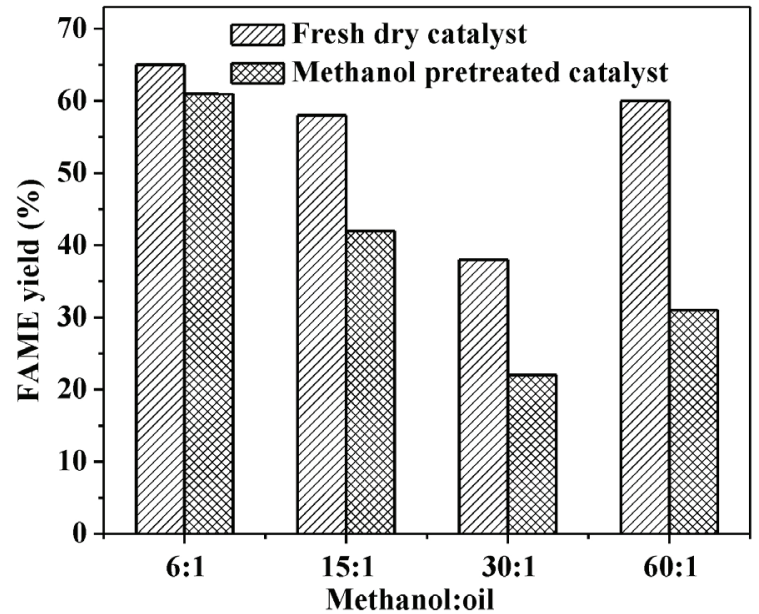

Fig. 4 - Effect of catalyst pretreatment on FAME yield from Karanja oil for different methanol to oil ratios. Reaction conditions: catalyst amount $=18 \mathrm{wt} \%$ of oil; temperature $=393 \mathrm{~K}$; $r p m=750$; reaction mixture volume $=341 \mathrm{~mL}$.

Amberlyst 15 with methanol decreased the FAME yield by $42 \%, 22 \%$, and $31 \%$ at methanol to oil ratios of $15: 1,30: 1$, and $60: 1$, respectively. For a methanol to oil ratio of $6: 1$, the FAME yield for the as-received and methanol-pretreated catalysts were within experimental error and ranged from $65 \%$ (as-received) to $61 \%$ (methanol-pretreated). These results revealed that lower methanol to oil ratio and the as-received Amberlyst15 catalyst were most suitable for FAME production. However, the non-monotonic change in FAME yield with the increase in methanol to oil ratio was still present.

\section{Characterization of pretreated Amberlyst15}

During the above experiments, it was observed that Amberlyst 15 catalysts disintegrated during several FAME production reactions. Furthermore, while adding methanol and oil to the Amberlyst15 catalyst, a hissing sound and heating of the vessel were observed. To explore the effect of methanol to oil ratio, a known amount of Amberlyst 15 catalyst was mixed with the required amount of methanol and oil in a beaker, and agitated at room temperature. Indeed, disintegration of the Amberlyst 15 catalyst occurred in some cases and the disintegration was more pronounced at higher methanol to oil ratios. The SEM micrographs of the as-received Amberlyst 15 catalysts and the catalyst after methanol pretreatment are shown in Fig. 5. The micrographs in Fig. 5 reveal that, for a methanol to oil ratio of 15:1 and higher, severe disintegration of the Amberlyst 15 catalysts occurred. In contrast, for a methanol to oil ratio of $6: 1$, disintegration of Amberlyst 15 was minimal. It appears that the disintegration of Amberlyst15 at methanol to oil ratios higher than 6:1 was the cause for the non-monotonic change in FAME yield when the methanol to oil ratios was increased. 

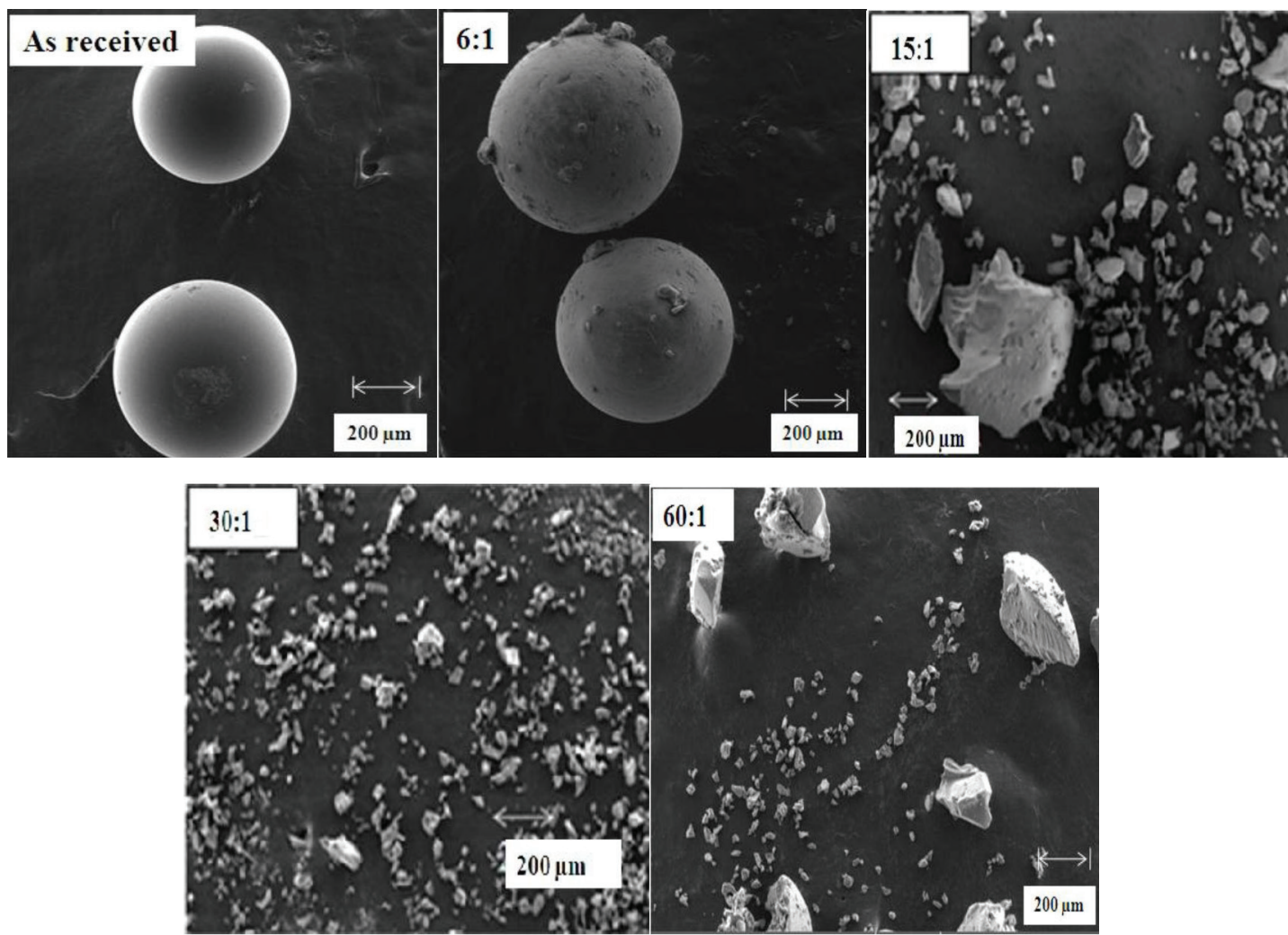

Fig. 5 - SEM analysis of Amberlyst15 (as-received) catalyst and methanol pretreatment with 6:1, 15:1,30:1, and 60:1 methanol to oil ratio

\section{Effect of grinding Amberlyst15}

To confirm the decrease in FAME yield due to disintegration of the Amberlyst15 catalyst, the as-received catalyst was ground to a powder in a mortar and pestle. The FAME production reaction was then carried out with the powdered catalyst using a methanol to oil ratio of $6: 1$. The FAME yield achieved using the powdered catalyst as a function of reaction times was compared (Fig. 6) with the FAME yield achieved when the as-received Amberlyst 15 catalyst was used as the catalyst. Fig. 6 reveals that the powdered Amberlyst 15 catalyst produced a much lower amount of FAME. To explore the reasons for the decrease in FAME yield, the surface area, pore volume, and TGA of the as-received and powdered catalysts were determined and presented in Table 4 (surface area and pore volume) and Fig. 7 (TGA). Table 4 shows that by grinding Amberlyst 15 the surface area and mesopore volume decreased. It appeared that by grinding Amberlyst 15 the mesopore structure was destroyed causing a decrease in surface area. The TGA of the samples shown in Fig. 7 revealed a similar weight loss for both the samples, suggesting that the chemical nature of the Amberlyst15 sample was retained. Thus, the decrease in surface area of the powdered Amberlyst 15 caused by the destruction of the mesopore structure was responsible for the decrease in FAME yield at methanol to oil ratios greater than $6: 1$.
The FAME yield using powdered Amberlyst15 catalyst and a methanol to oil ratio of $6: 1$ was compared to the FAME yield observed for methanol to oil ratios of $30: 1$ and $60: 1$ in Fig. 8. Fig. 8 shows that the FAME yield increased with the increase in methanol to oil ratio. Such a monotonic increase in FAME yield with the increase in methanol to oil was expected as discussed previously. Thus, the non-monotonic change in FAME yield observed

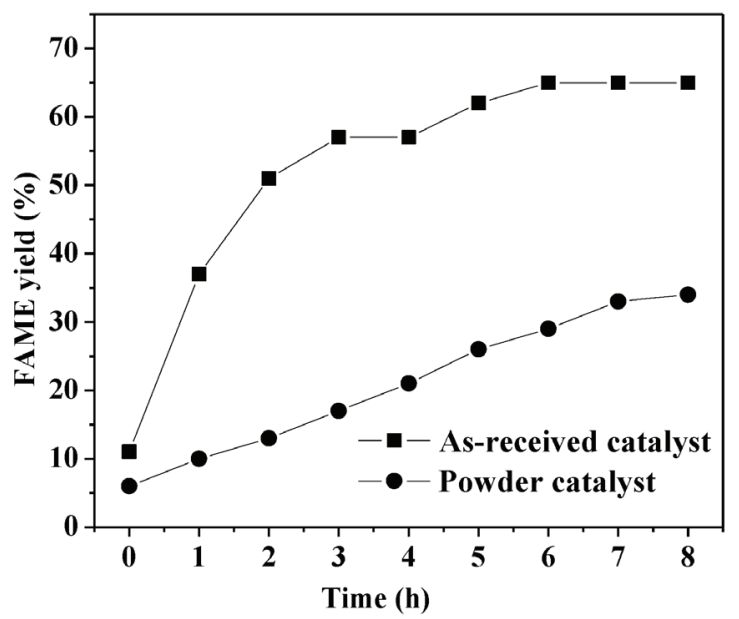

Fig. 6-FAME yield from Karanja oil at different reaction times showing the effect of grinding the Amberlyst 15 catalyst. Reaction conditions: catalyst amount $=18 \mathrm{wt} \%$ of oil; temperature $=393 \mathrm{~K} ; \mathrm{rpm}=750$; time $=8 \mathrm{~h}$; methanol:oil $=6: 1$. 


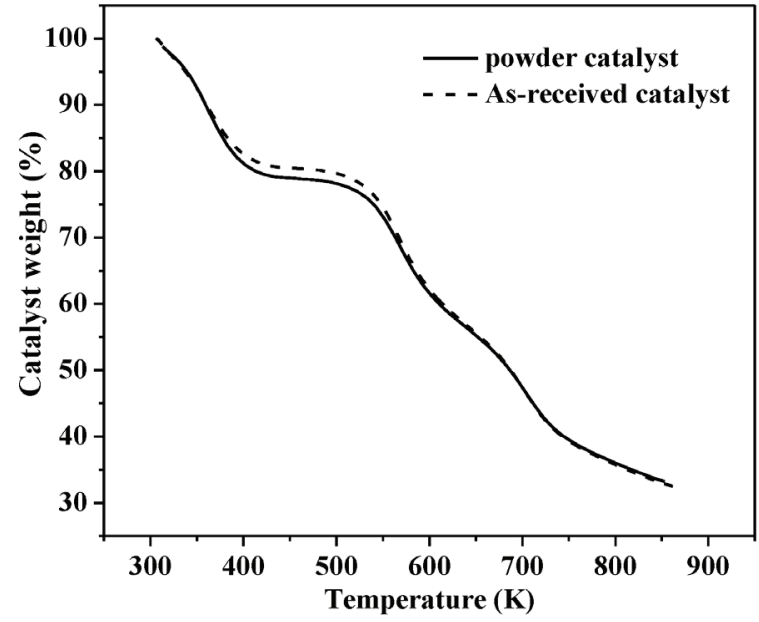

Fig. 7 - TGA of as-received and powdered Amberlyst15

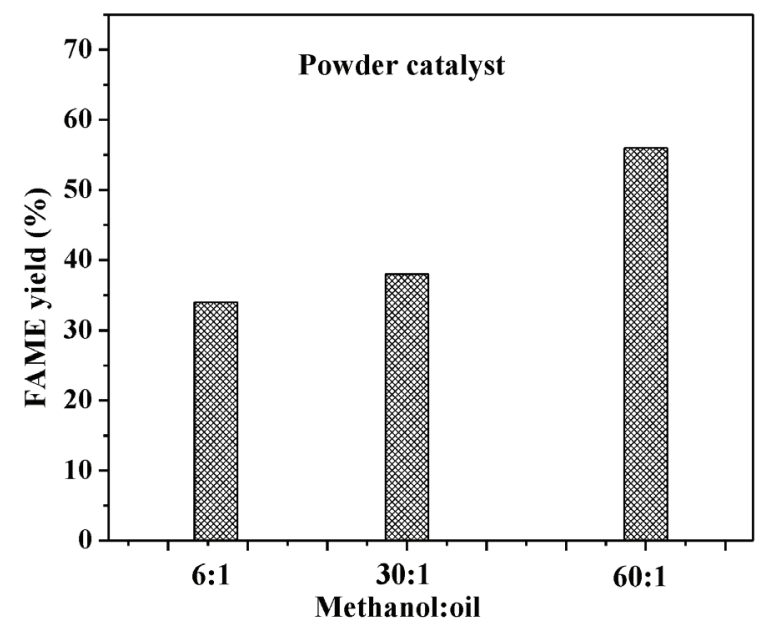

Fig. 8-FAME yield at different methanol to oil ratios for powdered Amberlyst15. Reaction conditions: catalyst amount $=$ $18 \mathrm{wt} \%$ of oil; temperature $=393 \mathrm{~K} ; \mathrm{rpm}=750 ;$ time $=8 \mathrm{~h}$; reaction mixture volume $=341 \mathrm{~mL}$.

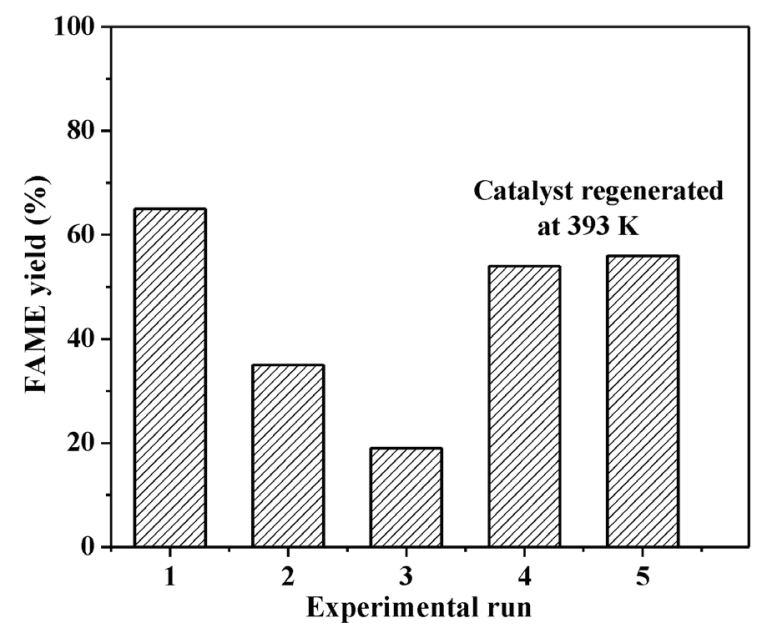

Fig. 9 - FAME yield from Karanja oil with different batches showing deactivation and regeneration of the Amberlyst15 catalyst. Reaction conditions: Karanja oil $=250.79 \mathrm{~g} ;$ methanol to oil ratio $=6: 1$; catalyst amount $=18 \mathrm{wt} \%$ of oil; temperature $=393 \mathrm{~K} ; \mathrm{rpm}=750 ;$ time $=8 \mathrm{~h}$. with the increase in methanol to oil ratio in Fig. 2 and Table 1, was due to the decrease in surface area of the disintegrated Amberlyst15 catalysts, which were formed at high methanol to oil ratios. Furthermore, disintegration of Amberlyst15 catalysts at high methanol to oil ratios has not been previously reported, and needs to be considered for proper design of a biodiesel production unit from non-edible oils using Amberlyst15 catalysts.

\section{Reusability test for Amberlyst15 catalyst}

The above study revealed that the Amberlyst15 catalyst was least affected during FAME production from Karanja oil at a methanol to oil ratio of 6:1. The reusability of the Amberlyst15 catalyst for FAME production from Karanja oil was then tested by carrying out the reaction with a methanol to oil of $6: 1$. The results of the reusability tests are shown in Fig. 9. After the first run, a FAME yield of $65 \%$ was achieved. Filtering the catalyst and carrying out the FAME production reaction with the filtered catalyst and fresh Karanja oil resulted in a drop in FAME yield to $35 \%$. Additional reuse of the spent catalyst resulted in a further decrease in FAME yield to $19 \%$. Following the third reuse, the Amberlyst 15 catalyst was heated in a furnace at $393 \mathrm{~K}$ for $4 \mathrm{~h}$. The choice of $393 \mathrm{~K}$ was based on the maximum operating temperature for Amberlyst15 as specified by the supplier. ${ }^{42}$ Upon heating Amberlyst 15 , the catalytic activity was mostly regained and a FAME yield of $54 \%$ was achieved. A $54 \%$ FAME yield was still lower than the FAME yield of $65 \%$ achieved by using the as-received catalyst, and a FAME yield of $60 \%$ achieved by using a methanol pretreated catalyst. The spent catalyst was again regenerated at $393 \mathrm{~K}$ for $4 \mathrm{~h}$ and a FAME yield of $56 \%$ was achieved. The decrease in catalyst activity for a methanol to oil ratio of $6: 1$ with reuse appeared to be due to the adsorption, and the loss in catalytic activity was reversible. Thus, using a methanol to oil ratio of 6:1 the physical characteristics of the Amberlyst15 catalyst were retained. However, the catalyst deactivated with reuse and the activity of the spent catalyst was mostly recovered by regeneration at $393 \mathrm{~K}$.

\section{Estimation of kinetic parameters}

The above results showed that the physical structure of the Amberlyst15 catalyst was retained when a methanol to oil ratio of 6:1 was used for FAME production. Using this methanol to oil ratio, the kinetic parameters for triglycerol consumption were determined using the methodology mentioned above. The reaction was carried out at 353,373 , and $393 \mathrm{~K}$, and the FAME yields and glyceridic conversions from Karanja oil were determined at various 


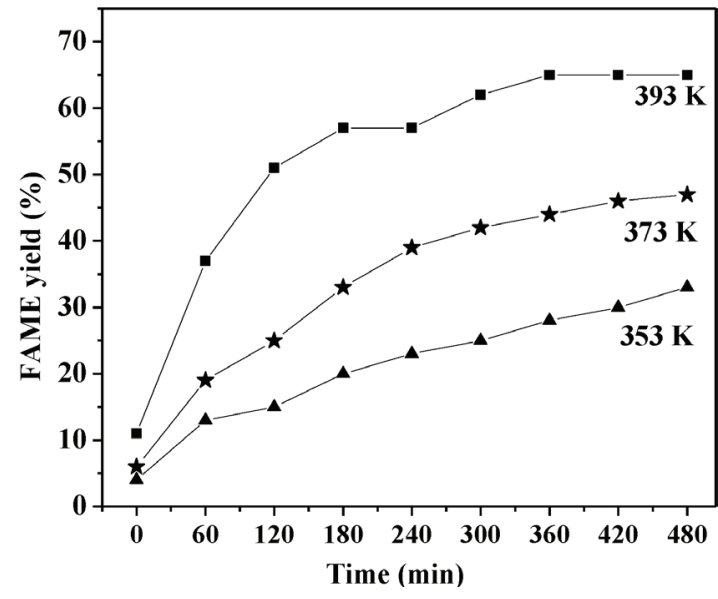

Fig. 10 - FAME yield from Karanja oil at different reaction times showing the effect of temperature. Reaction conditions: catalyst amount $=18 \mathrm{wt} \%$ of oil; temperature $=393 \mathrm{~K} ; \mathrm{rpm}=$ 750; time $=8$ h; methanol:oil $=6: 1$, reaction mixture volume $=341 \mathrm{~mL}$.

times. The FAME yields determined by considering (i) $\alpha-\mathrm{CH}_{2}$ and methyl ester protons, and (ii) glyceridic and methyl ester protons, differed by less than $2 \%$, indicating the absence of side products. The results of FAME yields as a function of reaction time and temperature are shown in Fig. 10. As expected, the FAME yield increased with the increase in reaction time and reaction temperature.

Using the FAME yield as a function of time, the rate of triglycerol consumption was calculated at each temperature, and the values of $k$ were obtained using integral analysis, and are presented in Table 5. During integral analysis, the best fit was obtained for $n=2$. Table 5 reveals that the values of $k$ were obtained with $R^{2}$ values greater than 0.92 . Using the values of $k$ at different temperatures, activation energy of $41.7 \mathrm{~kJ} \mathrm{~mol}^{-1}\left(R^{2}=0.985\right)$ was obtained, which was used as the initial guess for non-linear regression. Furthermore, the initial value of $k_{m}$ and $n$ were $0.15\left(\mathrm{~L} \mathrm{~mol}^{-1} \mathrm{~h}^{-1}\right)$ and 2 , respectively. Using these initial values of the parameters, the values of $k_{m}, E / R$ and $n$ along with their $95 \%$ confidence limits were determined by non-linear regression, and are presented in Table 6. Table 6 reveals that the values of the parameters were determined with a high degree of confidence. The parity plot shown in Fig. 11 also reveals a close correspondence between the predicted value of the derivative and the experimentally determined value of the derivative. Furthermore, based on non-linear re-

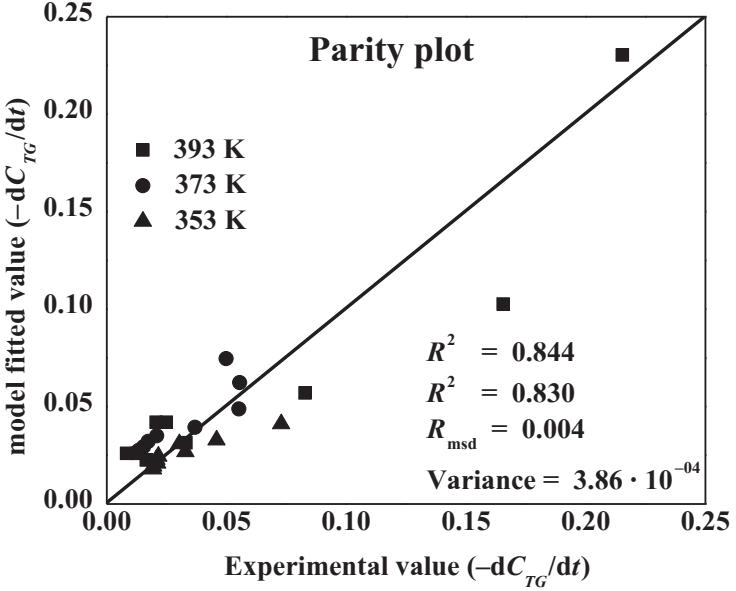

Fig. 11 - Parity plot between predicted and experimental values of $-\frac{d C_{T G}}{d t}$ for Karanja oil

gression, $E$ was $54.9 \mathrm{~kJ} \mathrm{~mol}^{-1}, k_{m}$ was $0.19 \mathrm{~L} \mathrm{~mol}^{-1} \mathrm{~h}^{-1}$, and $n$ was close to two. Previous studies for the values of activation energy and order for the single-step FAME production from Karanja oil using Amberlyest15 are not available and comparison was difficult. For two esterification reactions using Amberlyst15 catalysts, activation energies of 54.8 and $55.4 \mathrm{~kJ} \mathrm{~mol}^{-1}$ were determined. ${ }^{26,27}$ Furthermore, an overall activation energy of $60.7 \mathrm{~kJ} \mathrm{~mol}^{-1}$ for triacetin + oleic acid conversion using a heterogeneous catalyst was also reported. ${ }^{43}$ All these values of activation energies were similar to the activation energy determined in the present study. An initial turnover frequency (TOF) of $1.9 \cdot 10^{-3}$ to $6.4 \cdot 10^{-3} \mathrm{~s}^{-1}$ was reported for the transesterification of triacetin at $333 \mathrm{~K}^{44}$ Extrapolating the rate expression of the present study to $333 \mathrm{~K}$ and using supplier specified acid strength of $4.7 \mathrm{eq} \mathrm{kg}^{-1}$, an initial TOF of $\sim 1.0 \cdot 10^{-3} \mathrm{~s}^{-1}$ was obtained, which was slightly lower than the TOF value reported previously for the transesterification of triacetin.

The effect of internal and external mass transfer is a concern for biodiesel production using heterogeneous catalysts. ${ }^{44}$ In the present study, the use of tetrahydrofuran (THF) as a co-solvent had no effect on the FAME yield versus reaction time plot, suggesting the absence of external mass transfer limitations. This plot is not shown for brevity. The presence of internal mass transfer limitations can also have an effect on the catalytic activity. The

Table 4 - Surface area and various pore volumes of different forms of Amberlyst 15

\begin{tabular}{l|c|c|c|c|c}
\hline $\begin{array}{c}\text { Physical form of the } \\
\text { catalyst }\end{array}$ & $\begin{array}{c}\text { Surface area } \\
\left(\mathrm{m}^{2} \mathrm{~g}^{-1}\right)\end{array}$ & $\begin{array}{c}\text { Total Pore } \\
\text { vol. }\left(\mathrm{mL} \mathrm{g}^{-1}\right)\end{array}$ & $\begin{array}{c}\text { Micropore vol. } \\
\left(\mathrm{mL} \mathrm{g}^{-1}\right)\end{array}$ & $\begin{array}{c}\text { Mesopore vol. } \\
\left(\mathrm{mL} \mathrm{g}^{-1}\right)\end{array}$ & $\begin{array}{c}\text { Macropore vol. } \\
\left(\mathrm{mL} \mathrm{g}^{-1}\right)\end{array}$ \\
\hline As-received sample & 70 & 0.50 & 0.0 & 0.49 & 0.01 \\
Powder sample & 19 & 0.16 & 0.0 & 0.15 & 0.01 \\
\hline
\end{tabular}


Table 5 -Kinetic parameters for the power law model given by eq. 1 using integral analysis for $n=2$. The $95 \%$ confidence limits are given in parenthesis and $R^{2}$ values are also given in the last column.

\begin{tabular}{c|c|c}
\hline $\begin{array}{c}\text { Reaction } \\
\text { temperature }\end{array}$ & $\begin{array}{c}k\left(\mathrm{~L} \mathrm{~mol}^{-1} \mathrm{~h}^{-1}\right) \\
(95 \% \text { confidence limit })\end{array}$ & $R^{2}$ \\
\hline $353 \mathrm{~K}$ & 0.063 & 0.987 \\
& $(0.006)$ & \\
$373 \mathrm{~K}$ & 0.116 & 0.969 \\
& $(0.021)$ & \\
$393 \mathrm{~K}$ & 0.269 & 0.924 \\
\hline
\end{tabular}

Table 6 - Kinetic parameter values for the power law model given by eq. 4 and the $95 \%$ confidence limits

\begin{tabular}{c|c|c|c}
\hline $\begin{array}{c}\text { Kinetic } \\
\text { parameter }\end{array}$ & Initial guess & $\begin{array}{c}\text { Converged } \\
\text { value }\end{array}$ & $\begin{array}{c}95 \% \text { confidence } \\
\text { limits }\end{array}$ \\
\hline$k_{m}$ & 0.149 & 0.19106 & $7.9 \cdot 10^{-5}$ \\
$n$ & 2 & 2.3421 & $7.9 \cdot 10^{-4}$ \\
$E / R$ & 5015 & 6606 & 3.3 \\
\hline
\end{tabular}

high value of activation energy obtained in the present study and those of the previous studies referred to previously, suggest the absence of internal mass transfer limitations. For liquid phase diffusion, limited reaction activation energy of about $5 \mathrm{~kJ} \mathrm{~mol}^{-1}$ would be expected. Thus, it seems that the kinetic parameter values were consistent with those reported in the literature.

\section{Conclusion}

A single-step process for converting Karanja oil to FAME using Amberlyst15 as a catalyst was explored. The effect of methanol to oil ratio on the FAME yield at $393 \mathrm{~K}$ was unusual since the FAME yield followed a non-monotonic change when the methanol to oil ratio was increased. Such a non-monotonic behavior was also observed for Jatropha, Linseed, and Soybean oils and appeared to be due to the catalyst properties. At methanol to oil ratios of 15 and above, the Amberlyst 15 catalyst disintegrated. Disintegration of the Amberlyst15 catalyst gave rise to a loss in surface area, decrease in mesoporous volume and loss in catalytic activity. The disintegration of Amberlyst15 catalysts at high methanol to oil ratios was not reported previously and needs to be considered for proper design of a FAME production unit from non-edible oils using Amberlyst 15 as acid catalysts. Thus, a methanol to oil ratio of $6: 1$ and a temperature of $393 \mathrm{~K}$ were the most appropriate reaction conditions for converting Karanja oil to FAME without losing the physical attributes of Amberlyst15 catalyst. Under these reaction conditions, the Amberlyst15 catalyst still deac- tivated when reused. However, this deactivation was reversible since the FAME yield was mostly recovered by heating the Amberlyst 15 catalyst up to $393 \mathrm{~K}$. Based on the reaction conditions, the kinetic parameters for a power law were also successfully determined. An activation energy of $54.9 \mathrm{~kJ} \mathrm{~mol}^{-1}$, a reaction order of close to two and a rate constant at $373 \mathrm{~K}$ of $0.19 \mathrm{~L} \mathrm{~mol}^{-1} \mathrm{~h}^{-1}$ were estimated. For Karanja oil, the power law model took the form:

$-r_{T G}=0.19 C_{T G}^{2.3} \exp \left[-6606\left(\frac{1}{T}-\frac{1}{373}\right)\right] \mathrm{mol} \mathrm{L}^{-1} \mathrm{~h}^{-1}$.

\section{References}

1. Tomasevic, A. V., Siler-Marinkovic, S. S., Methanolysis of used frying oil, Fuel Process. Technol. 81 (2003) 1. doi: https://doi.org/10.1016/S0378-3820(02)00096-6

2. Vicente, G., Martınez, M., Aracil, J., Integrated biodiesel production: A comparison of different homogeneous catalysts systems, Bioresour. Technol. 92 (2004) 297. doi: https://doi.org/10.1016/j.biortech.2003.08.014

3. Arzamendi, G., Campo, I., Arguinarena, E., Sanchez, M., Montes, M., Gandia, L. M., Synthesis of biodiesel with heterogeneous $\mathrm{NaOH} /$ alumina catalysts: Comparison with homogeneous $\mathrm{NaOH}$, Chem. Eng. J. 134 (2007) 123.

4. Xie, W., Peng, H., Chen, L., Transesterification of soybean oil catalyzed by potassium loaded on alumina as a solid-base catalyst, Appl. Catal. A 300 (2006) 67. doi: https://doi.org/10.1016/j.apcata.2005.10.048

5. Sani, Y. M., Daud, W. M. A. W., Aziz, A. R. A., Activity of solid acid catalysts for biodiesel production: A critical review, Appl. Catal. A 470 (2014) 140. doi: https://doi.org/10.1016/j.apcata.2013.10.052

6. Melero, J. A., Iglesias, J., Morales, G., Heterogeneous acid catalysts for biodiesel production: current status and future challenges, Green Chem. 11 (2009) 1285. doi: https://doi.org/10.1039/b902086a

7. Bournay, L., Casanave, D., Delfort, B., Hillion, G., Chodorge, J. A., New heterogeneous process for biodiesel production: A way to improve the quality and the value of the crude glycerin produced by biodiesel plants, Catal. Today 106 (2005) 190 doi: https://doi.org/10.1016/j.cattod.2005.07.181

8. Serio, M. D., Tesser, R., Casale, L., D'Angelo, A., Trifuoggi, $M$., Santacesaria, E., Heterogeneous catalysis in biodiesel production: The influence of leaching, Top. Catal. 53 (2010) 811. doi: https://doi.org/10.1007/s11244-010-9467-y

9. Srivastava, P. K., Verma, M., Methyl ester of karanja oil as an alternative renewable source energy, Fuel 87 (2008) 1673. doi: https://doi.org/10.1016/j.fuel.2007.08.018

10. Jain, S., Sharma, M. P., Rajvanshi, S., Acid base catalyzed transesterification kinetics of waste cooking oil, Fuel Process. Technol. 92 (2011) 32 doi: https://doi.org/10.1016/j.fuproc.2010.08.017

11. Perego, C., Bianchi, D., Biomass upgrading through acidbase catalysis, Chem. Eng. J. 161 (2010) 314. doi: https://doi.org/10.1016/j.cej.2010.01.036

12. Meher, L. C., Sagar, D. V., Naik, S. N., Technical aspects of biodiesel production by transesterification - a review, Renewable sustainable Energy rev. 10 (2006) 248. doi: https://doi.org/10.1016/j.rser.2004.09.002 
13. Marchetti, J. M., Miguel, V. U., Errazu, A. F., Possible methods for biodiesel production, Renewable sustainable Energy rev. 11 (2007) 1300. doi: https://doi.org/10.1016/j.rser.2005.08.006

14. Hanh, H. D., Dong, N. T., Okitsu, K., Nishimura, R., Mae$d a, Y$., Biodiesel production by esterification of oleic acid with short-chain alcohols under ultrasonic irradiation condition, Renewable Energy 34 (2009) 780.

doi: https://doi.org/10.1016/j.renene.2008.04.001

15. Thiruvengadaravi, K. V., Nandagopal, J., Bala, V. S. S., Kirupha, S. D., Vijayalakshmi, P., Sivanesan, S., Kinetic study of the esterification of free fatty acids in non-edible Pongamia pinnata oil using acid catalyst, Indian Journal of Science and Technology 2 (2009) 20.

16. Su, F., Guo, Y., Advancements in solid acid catalysts for biodiesel production, Green Chem. 16 (2014) 2934. doi: https://doi.org/10.1039/C3GC42333F

17. Shikha, K., Rita, C. Y. J., Biodiesel production from non edible-oils: A Review J. Chem. Pharm. Res. 4(9) (2012) 4219.

18. Sharma, Y. C., Singh, B., Korstad, J., High yield and conversion of biodiesel from a nonedible feedstock (Pongamia pinnata), J. Agric. Food Chem. 58 (2010) 242. doi: https://doi.org/10.1021/jf903227e

19. Vivek, Gupta, A. K., Biodiesel production from karanja oil, J. Sci. Ind. Res. 63 (2004) 39.

20. Khayoon, M. S., Hameed, B. H., Single-step esterification of crude karanja (Pongamia pinnata) oil to fatty acid methyl esters over mesostructured SBA-16 supported 12- molybdo phosphoric acid catalyst, Fuel Process. Technol. 114 (2013) 12.

doi: https://doi.org/10.1016/j.fuproc.2013.03.014

21. Harmer, M. A., Sun, $Q$., Solid acid catalysis using ion-exchange resins, Appl. Catal. A 221 (2001) 45.

22. Andrijanto, E., Dawson, E. A., Brown, D. R., Hypercrosslinked polystyrene sulphonic acid catalysts for the esterification of free fatty acids in biodiesel synthesis, Appl. Catal. B 115-116 (2012) 261. doi: https://doi.org/10.1016/j.apcatb.2011.12.040

23. Gupta, A. K, Deo, G., Biodiesel production from a free fatty acid containing Karanja oil by a single-step heterogeneously catalyzed process, Int. J. Green Energy 13(5) (2016) 489. doi: https://doi.org/10.1080/15435075.2014.977440

24. Talukder, M. M. R., Wu, J. C., Lau, S. K., Cui, L. C., Shimin, G., Lim, A., Comparison of Novozym 435 and Amberlyst 15 as heterogeneous catalyst for production of biodiesel from palm fatty acid distillate, Energy Fuels 23 (2009) 1. doi: https://doi.org/10.1021/ef8006245

25. Singh, N., Kumar, R., Sachan, P. K., Kinetic Study of catalytic esterification of butyric acid and ethanol over Amberlyst 15, ISRN Chemical Engineering, Hindawi Publishing Corporation, Article ID 520293(2013) 6.

26. Sharma, M., Wanchoo, R. K., Toor, A. P., Amberlyst 15 catalyzed esterification of nonanoic acid with 1-propanol: Kinetics, modeling, and comparison of its reaction kinetics with lower alcohols, Ind. Eng. Chem. Res. 53 (2014) 2167. doi: https://doi.org/10.1021/ie402407r

27. Huang, Y.-S., Sundmacher, K., Kinetics study of propyl acetate synthesis reaction catalyzed by Amberlyst 15, Int. J. Chem. Kinet. 39 (2007) 245. doi: https://doi.org/10.1002/kin.20236

28. Kumar, R., Tiwari, P., Garg, S., Alkali transesterification of linseed oil for biodiesel production, Fuel 104 (2013) 553. doi: https://doi.org/10.1016/j.fuel.2012.05.002

29. Guillen, M. D., Ruiz, A., High resolution $1 \mathrm{H}$ nuclear magnetic resonance in the study of edible oils and fats, Trends Food Sci. Technol. 12 (2001) 328. doi: https://doi.org/10.1016/S0924-2244(01)00101-7
30. Knothe, G., Monitoring a progressing transesterification reaction by fiber-optic near infrared spectroscopy with correlation to $1 \mathrm{H}$ nuclear magnetic resonance spectroscopy, J. Am. Oil Chem. Soc. 77 (2000) 489. doi: https://doi.org/10.1007/s11746-000-0078-5

31. Routray, K., Reddy, K. R. S. K., Deo, G., Oxidative dehydrogenation of propane on $\mathrm{V}_{2} \mathrm{O}_{5} / \mathrm{Al}_{2} \mathrm{O}_{3}$ and $\mathrm{V}_{2} \mathrm{O}_{5} / \mathrm{TiO}_{2}$ catalysts: understanding the effect of support by parameter estimation, Appl. Catal. A 265 (2004) 103.

doi: https://doi.org/10.1016/j.apcata.2004.01.006

32. Rezende, S. M. D., Reis, M. D. C., Reid, M. G., Jr., P. L. C. S., Coutinho, F. M. B., Gil, R. A. D. S. S., Lachter, E. R., Transesterification of vegetable oils promoted by poly(styrene-divinylbenzene) and poly(divinylbenzene), Appl. Catal. A 349 (2008) 198. doi: https://doi.org/10.1016/j.apcata.2008.07.030

33. Reis, S. C. M. D., Lachter, E. R., Nascimento, R. S. V., Jr., J. A. R., Reid, M. G., Transesterification of brazilian vegetable oils with methanol over ion-exchange resins, J. Am. Oil Chem. Soc. 82 (2005) 9.

34. Paterson, G., Issariyakul, T., Baroi, C., Bassi, A., Dalai, A., Ion- exchange resins as catalyst in transesterification of triolein, Catal. Today 212 (2013) 157. doi: https://doi.org/10.1016/j.cattod.2012.10.013

35. Kim, H.-J., Kang, B.-S., Kim, M.-J., Park, Y. M., Kim, D.K., Lee, J.-S., Lee, K. Y., Transesterification of vegetable oil to biodiesel using heterogeneous base catalyst, Catal. Today 93-95 (2004) 315. doi: https://doi.org/10.1016/j.cattod.2004.06.007

36. Mohammed-Dabo, I. A., Ahmad, M. S., Hamza, A., Muazu, K., Aliyu, A., Co-solvent transesterification of Jatropha curcas seed oil, Journal of Petroleum Technology and Alternative Fuels 3(4) (2012) 42.

37. Srivastava, P. K., Verma, M., Methyl ester of karanja oil as an alternative renewable source energy, Fuel 87 (2008) 1673 . doi: https://doi.org/10.1016/j.fuel.2007.08.018

38. Graboski, M. S., McCormick, R. L., Combustion of fat and vegetable, oil derived fuels in diesel engines, Prog. Energy Combust. Sci. 24 (1998) 125. doi: https://doi.org/10.1016/S0360-1285(97)00034-8

39. Khayoon, M. S., Olutoye, M. A., Hameed, B. H., Utilization of crude karanja (Pongamia pinnata) oil as a potential feedstock for the synthesis of fatty acid methyl esters, Bioresour. Technol. 111 (2012) 175. doi: https://doi.org/10.1016/j.biortech.2012.01.177

40. Juana, J. C., Kartika, D. A., Wu, T. Y., Hin, T.-Y. Y., Biodiesel production from jatropha oil by catalytic and non-catalytic approaches: An overview, Bioresour. Technol. 102 (2011) 452. doi: https://doi.org/10.1016/j.biortech.2010.09.093

41. Lien, Y.-S., Hsieh, L.-S., Wu, J. C. S., Biodiesel synthesis by simultaneous esterification and transesterification using oleophilic acid catalyst, Ind. Eng. Chem. Res. 49 (2010) 2118. doi: https://doi.org/10.1021/ie901496h

42. http://www.sigmaaldrich.com/catalog/product/si$\mathrm{al} / 216380$ ?lang $=$ en\&region $=\mathrm{IN}$.

43. Lopez, D. E., Jr., J. G. G., Bruce, D. A., Furuta, S., Transesterification of triacetin with methanol on Nafion ${ }^{\circledR}$ acid resins, J. Catal. 245 (2007) 381. doi: https://doi.org/10.1016/j.jcat.2006.10.027

44. Lopez, D. E., Jr., J. G. G., Bruce, D. A., Lotero, E., Transesterification of triacetin with methanol on solid acid and base catalysts, Appl. Catal. A 295 (2005) 97. 